\title{
Small-for-gestational age Portuguese babies: The effect of childhood social environment, growth and adult socioeconomic conditions
}

\author{
Sofia Correia *, Henrique Barros \\ Department of Clinical Epidemiology, Predictive Medicine and Public Health, University of Porto Medical School, Al Prof. Hernani Monteiro, 4200-319 Porto, Portugal \\ EPIUnit - Institute of Public Health, University of Porto, Rua das Taipas, 135-139, 4050-600 Porto, Portugal
}

\section{A R T I C L E I N F O}

Available online 6 December 2014

\section{Keywords:}

Socioeconomic trajectories

Growth

Small-for-gestational age

Education

\section{A B S T R A C T}

Objective. We aimed to estimate the extent to which differences in small-for-gestational age (SGA) according to maternal socioeconomic position (SEP) and anthropometrics are accounted for childhood background.

Methods. Adult mothers of singletons $(n=6893)$ recruited in 2005/2006 in Porto, Portugal self-reported data on socio-demographics. Grandparents' education and social class were used to characterise childhood social environment. Maternal education and marital status were used as adult SEP indicators. Height was categorised according to the 10th and 90th percentiles. The odds of SGA according to adult SEP and height were stratified by childhood conditions.

Results. SGA (14.5\%) was less likely in taller [vs. 10th-90th percentiles: 0.62 (95\% confidence interval (CI): 0.46-0.83)], more educated [vs. low: 0.77 (0.65-0.90)] and in married women [vs. single: $0.64(0.47-0.86)$ ]. No association was found between childhood social conditions and SGA. The protection provided by maternal education was found in women from deprived childhood backgrounds but not in those with more advantage conditions. Shorter women were more likely to deliver SGA babies but the effect was stronger $\left(p_{\text {interaction }}<0.001\right.$ ) in those from least deprived childhood conditions.

Conclusions. Sufficient increase in education seems to overcome disadvantage earlier in life. Other pathological processes might impact physical development beyond social influence, having long lasting effects on SGA.

(c) 2014 Published by Elsevier Inc.

\section{Introduction}

Nutritional, behavioural and psychosocial factors are recognised determinants of intrauterine growth restriction (Kramer et al., 2000; Raisanen et al., 2013) which might explain the pervasive social inequalities in this outcome (Mortensen et al., 2008; Blumenshine et al., 2010). For several years, research suggests that more educated women (or those with higher income or socially-advantaged occupations) are more likely to seek prenatal care, to adopt healthier lifestyles during pregnancy and are less likely to be exposed to stressful events (Kramer et al., 2000).

The intergenerational transmission of social conditions and its impact on adult health may reflect a failure of modern societies in the discontinuation of social inequalities in health and emphasise the importance of focusing early in life (Graham and Power, 2004; Marmot et al., 2012). Most evidence suggests that childhood circumstances influence adult socioeconomic conditions and, consequently, adult health. Some authors argue that improving social status (upward mobility)

\footnotetext{
Abbreviations: SGA, small-for-gestational age; OR, odds ratio.

* Corresponding author at: Institute of Public Health, University of Porto, Rua das Taipas, 135-139, 4050-600 Porto, Portugal. Fax: + 351222061821.

E-mail address: scorreia@med.up.pt (S. Correia).
}

may represent a protective exposure to health while individuals who fall in the social hierarchy may be at increased risk of disease (Poulton et al., 2002). Childhood background is also likely to influence cognitive and physical development and health behaviours' acquisition resulting in health differentials later in life (Graham and Power, 2004).

Childhood social environment has been described to affect pregnancy outcomes, namely the delivery of low birthweight or preterm infants (Astone et al., 2007; Collins et al., 2003, 2009; Colen et al., 2006; Emanuel et al., 1992; Hypponen et al., 2004; Lumey and Stein, 1997). Maternal birthweight and physical growth (possibly reflecting unfavourable early childhood conditions) are known to influence the next generation birthweight. Some studies show that the relation is independent of childhood economic conditions (Collins et al., 2011), others report maternal social environment when in-utero (Emanuel et al., 1992; Hypponen et al., 2004; Lu and Halfon, 2003; Lawlor et al., 2003), together with social trajectories (Colen et al., 2006) to be important to explain forthcoming inequalities.

Over the past 50 years impressive changes in the socioeconomic and cultural context were observed in Portugal. The country faced the longest-standing dictatorship in Europe (1926-1974), a period of nearly inexistent social mobility, of highly illiterate population and high infant mortality rates. After the 1960s, and particularly after the 1974 revolution, social conditions improved, compulsory schooling increased and 
the National Health Service was launched, guaranteeing free universal access to care. After few decades, Portugal remains one of the least educated countries in Europe (Albert and Davia, 2011) but with health indicators similar to or better than the most European countries (Barreto, 2011).

In a context of such transformations it is not known if the association of social conditions with pregnancy outcomes is still reflecting childhood environment.

We aimed to estimate the extent to which differences in small-forgestational age (SGA) according to maternal socioeconomic position and anthropometrics are accounted for childhood social background.

\section{Methods}

This study is based in Generation XXI, a cohort of 8647 newborns recruited in 2005-2006 in Porto Metropolitan Area, north of Portugal (Alves et al., 2012; Larsen et al., 2013). Recruitment occurred at 5 public maternity units, responsible for $95 \%$ of all births in the region. During the hospital stay (within $72 \mathrm{~h}$ of delivery), resident women delivering live births were invited and $92 \%$ of mothers accepted to participate. Data on socio-demographic, lifestyles and pregnancy characteristics were collected in structured face-to-face interviews. Interviewers were part of the project staff, trained by the research team. Regular meetings were taken place to assure inter-observer consistency. Delivery- and newborn-related data were retrieved from medical records by the same interviewers. The study was approved by the University of Porto Medical School/ Hospital S. João Ethics Committee and a signed informed consent was required for all participants.

\section{Childhood, growth and adult social conditions}

Childhood socioeconomic characteristics were reported by the mothers using their 12 years of age as reference. Three indicators were used as proxies of childhood social environment: grandparents' highest education, childhood social class and family structure. Grandparents' highest academic level was categorised as low ( $\leq$ primary academic level), intermediate (secondary) and high (> secondary). Social class was previously defined considering maternal recall of grandparents' education and 11 family resources (house ownership, household heating, washing machine, television, telephone, housemaid, family car, bicycle, annual holidays, club membership and association affiliation) (Teixeira, 2013). By using latent class statistical modelling, three categories were obtained representing low/deprived (25\%), intermediate $50 \%$ ) or high/ advantaged (24\%) social class. Mothers reported if they were living with both, one or none of the grandparents.

Adult mothers' height was used as proxy of physical growth. Height was measured whenever possible, otherwise was copied from identity card. The 10 th $(<153.0 \mathrm{~cm})$ and 90th $(>169.0 \mathrm{~cm})$ percentiles of the sample distribution were estimated to categorise women.

Mothers' education and marital status at delivery were used to characterise adult socioeconomic position. Other indicators were available but were found to be highly correlated with education. Educational achievement was categorised as low ( $\leq$ primary level), intermediate (lower secondary) and high education ( $\geq$ upper secondary). Marital status was grouped as married, cohabitant and single.

\section{Small-for-gestational-age}

SGA was classified using Kramer et al.'s (2001) reference curves, considering sex-specific birthweight below the 10th percentile for each gestational age. Birthweight is routinely measured within $24 \mathrm{~h}$ after delivery. Gestational age is registered in medical files based on the biometric measurement of the ultrasound or, if not performed/available (15\%), on the last menstrual period.

\section{Confounding variables}

Maternal age and the number of previous pregnancies (gravidity) - 0, 1 and 2 or more - were used as confounders. Pre-pregnancy weight was reported by the mothers and was used as a confounder of the association between height and SGA. Potential mediating variables, such as smoking during pregnancy or pregnancy complications, were excluded from the models. Adjusting for mediators could introduce confounding where none existed before resulting in biased estimates (Robins and Greenland, 1992). Still, their distribution according to education and height is available in Supplementary Table 1.

\section{Data analysis}

Women over 20 years, reporting other occupation than being a student and delivering singletons were eligible $(n=7588)$. Those with missing data on the above-mentioned variables were excluded, resulting in 6863 women (Fig. 1). Additionally, 362 mothers were also excluded for the grandparents' education analysis because of unknown data. Included newborns were more likely to have more educated mothers (high: $47 \%$ vs. $42 \% ; \mathrm{p}=0.009$ ) and less educated grandparents (low education: $65 \%$ vs. $60 \%, \mathrm{p}<0.001$ ).

Proportions were compared using Chi-squared test. The association between each childhood socioeconomic indicator and adult education, marital status and height was estimated by fitting logistic regression models and presented as odds ratios (OR and 95\% confidence intervals). Maternal age was included as a confounder; for the association between childhood environment and adult education it was included as an interaction term (significant interaction for $\alpha=10 \%$ ).

The odds of SGA according to each adult and childhood indicator were estimated using logistic regression analysis adjusted for maternal age and gravidity (age and gravidity interactions were also tested). Because no association was found between family structure and adult conditions or between SGA and marital status, subsequent analyses were conducted for the remaining indicators. The association between maternal height and maternal education with SGA was evaluated for each stratum of childhood social environment. To analyse the independent effect of each mechanism, models were mutually adjusted. The association between height and SGA was also adjusted for pre-pregnancy weight. All models showed adequate fit, assessed by the Hosmer-Lemeshow goodness-of-fit test statistic ( $\mathrm{p}$-value $>0.05$ ).

\section{Results}

In this study $14.5 \%$ of the newborns $(n=997)$ were SGA. Almost $47 \%$ of the mothers completed upper secondary or higher education level while $31 \%$ only achieved primary education. About $2 / 3$ were married and $22 \%$ were cohabiting. Almost half were primigravidae and $13 \%$ were aged above 35 years. Nearly $68 \%$ of the grandparents only achieved primary or lower academic level. In childhood, $1 / 4$ of the mothers were from high social class and $85 \%$ were living with both parents (Table 1). More educated and taller mothers were more likely to be primigravidae, married, and normal/underweight and to use private prenatal care. More educated women were less likely to smoke (Supplementary Table 1 ).

In Table 2 the association between childhood conditions and adult education, marital status and height is presented. Mothers with intermediate and high educated parents (vs. low educated parents) were, respectively, 2 and 4 times more likely to present high education. The association between childhood social class and maternal education was even stronger. When compared to women from low childhood social class, those in intermediate or high levels were, respectively, 1.6 and 2.0 times more likely to be taller. Family structure was not related with adult conditions or maternal height. No childhood social indicator was related with marital status.

Independently of maternal age and gravidity, SGA was less likely to be present in taller [vs. 10th-90th percentiles: OR $=0.62(95 \% \mathrm{CI}$ : 0.46-0.83)], more educated [vs. low: $0.77(0.65-0.90)$ ] and in married women [vs. single: $0.64(0.47-0.86)]$. The association with marital status did not change after the adjustment for education [OR $=0.67$ (95\% CI: 0.49-0.90)]. Childhood social conditions were not associated with SGA (Table 3).

In Table 4 the association between SGA and maternal education and height is presented, stratified by childhood social environment. Mothers that increased to the highest education (vs. low education), but not those that moved to intermediate levels, showed lower risk of SGA: $32 \%$ less if they were from low social class; $21 \%$ if considering low grandparents' education. A non-significant decreased risk was found if mothers were from intermediate or high social class. Shorter women 


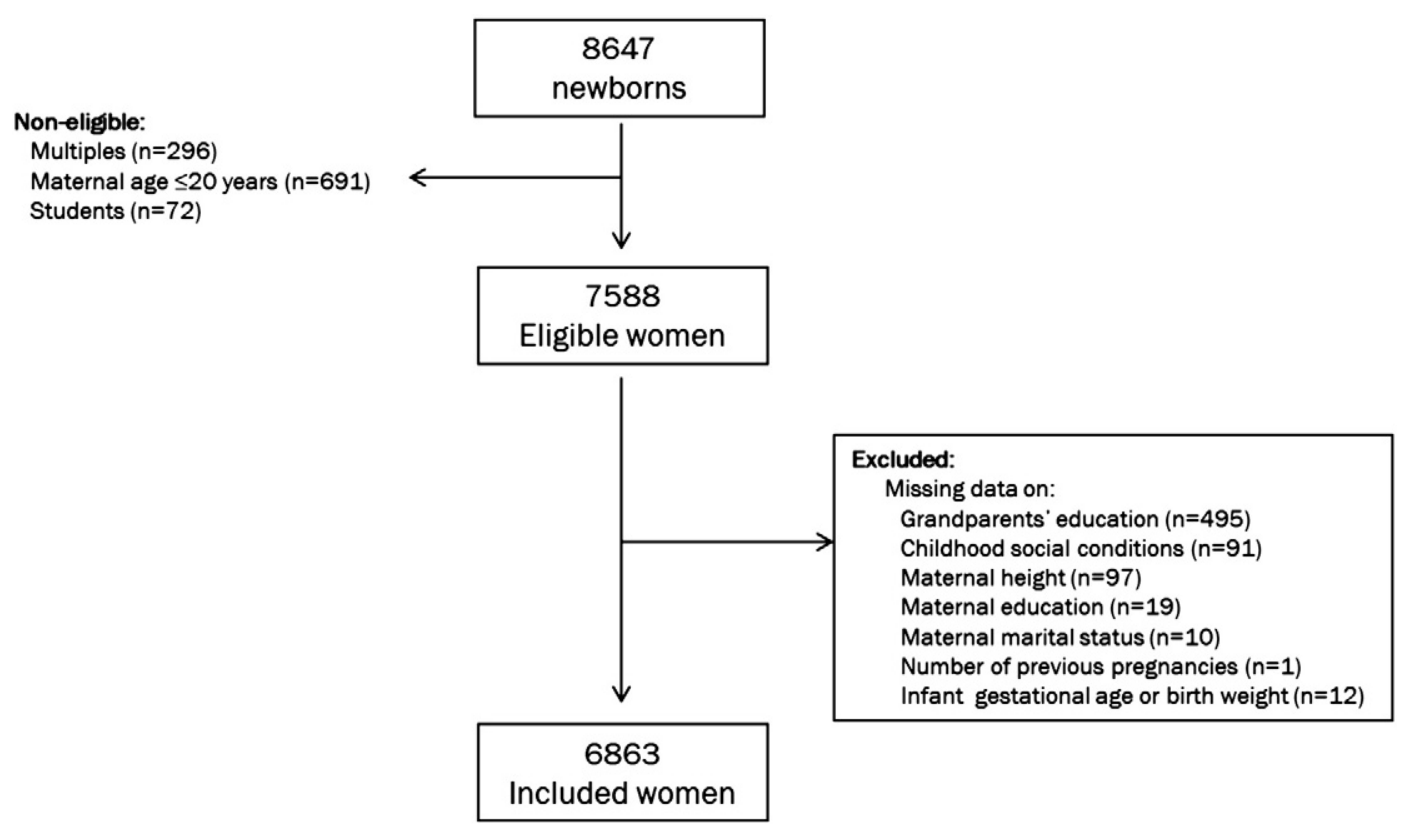

Fig. 1. Study participants.

were more likely to deliver SGA babies but the association was stronger among those from high childhood social class. Being taller decreased the odds of SGA among mothers from intermediate social class and low educated grandparents.

Table 1

Sample characteristics.

\begin{tabular}{|c|c|c|}
\hline & $\mathrm{n}$ & $\%$ \\
\hline Small-for-gestational age (SGA) & 997 & 14.5 \\
\hline \multicolumn{3}{|l|}{ Maternal level of education } \\
\hline Low $(\leq$ primary $)$ & 2124 & 31.0 \\
\hline Intermediate (lower secondary) & 1525 & 22.2 \\
\hline High ( $\geq$ upper secondary) & 3214 & 46.8 \\
\hline \multicolumn{3}{|l|}{ Marital status } \\
\hline Single & 279 & 4.1 \\
\hline Cohabiting & 1481 & 21.6 \\
\hline Married & 5103 & 74.4 \\
\hline \multicolumn{3}{|l|}{ Maternal height } \\
\hline$<10$ th percentile $(<153.0 \mathrm{~cm})$ & 674 & 8.8 \\
\hline $10-90$ th percentiles $(153.0-169.0 \mathrm{~cm})$ & 5547 & 80.8 \\
\hline$>90$ th percentile $(>169.0 \mathrm{~cm})$ & 642 & 9.4 \\
\hline \multicolumn{3}{|l|}{ Maternal age (years) } \\
\hline $21-25$ & 1321 & 19.2 \\
\hline $26-30$ & 2461 & 35.9 \\
\hline $31-35$ & 2181 & 31.8 \\
\hline$>35$ & 900 & 13.1 \\
\hline \multicolumn{3}{|l|}{ Gravidity (previous pregnancies) } \\
\hline None & 3081 & 44.9 \\
\hline One & 2453 & 35.8 \\
\hline Two or more & 1326 & 19.3 \\
\hline \multicolumn{3}{|l|}{ Grandparents' level of education $^{\mathrm{a}}$} \\
\hline Low $(\leq$ primary $)$ & 4443 & 68.3 \\
\hline Intermediate (secondary) & 1146 & 17.6 \\
\hline High (> secondary) & 912 & 14.0 \\
\hline \multicolumn{3}{|l|}{ Childhood social class ( 12 years) } \\
\hline Low & 1765 & 25.7 \\
\hline Intermediate & 3415 & 49.8 \\
\hline High & 1683 & 24.5 \\
\hline \multicolumn{3}{|l|}{ Childhood family structure (12 years) } \\
\hline No parents & 292 & 4.2 \\
\hline One parent & 733 & 10.7 \\
\hline Both parents & 5838 & 85.1 \\
\hline
\end{tabular}

a Excluding 362 mothers with unknown grandparents education.

\section{Discussion}

In this study, maternal education and height were both negatively associated with growth restriction. Although childhood social environment was not found to be associated with SGA, a sufficient increase in education seemed to overcome disadvantage earlier in life. Other characteristics beyond social conditions may mediate the relation between maternal height and SGA.

\section{Strengths and limitations}

This study used data from a large population-based sample allowing the assessment of different social contexts. Women grew up in periods of major socio-cultural changes which make this group of particular interest for the research of social influences in health.

Our target population was defined according to the maternal adult area of residence. Thus, they may be different from the population of origin when they were 12 years of age. Due to the urban nature of our sample and to the observed association between grandparents and mothers' education, it is possible that we over-represent more educated grandparents. Included hospitals were responsible for $95 \%$ of all region deliveries and women were invited in the basis of "first come first served". Although not directly relatable with participation bias, the high participation proportion may decrease the impact of that potential limitation.

Although exposures and outcome were collected at the same time, temporal direction is clear and we do not expect our sample to be biased according to these characteristics. However, retrospective recall of childhood conditions may lead to information bias. It has been described that highly educated participants report their parents' occupation and education more accurately (Ward, 2011). We cannot exclude classification errors but several family assets were used to define social class and different socioeconomic indicators were tested, corroborating the robustness of the results. In addition, their use improves the ability to understand how different components of social environment influence pregnancy outcomes.

The period for childhood exposure was set to the age of 12 . However, women might have been exposed to adversity in different periods of life which may influence health differently (Poulton et al., 2002; Sigle-Rushton et al., 2005). Also, the set of chosen indicators may not 
Table 2

Association between childhood socioeconomic environment and adult height and socioeconomic indicators from the 2005/2006 Portuguese birth cohort.

\begin{tabular}{|c|c|c|c|c|}
\hline & \multirow[t]{2}{*}{$\mathrm{n}$} & \multicolumn{3}{|l|}{ OR $[95 \% \mathrm{CI}]$} \\
\hline & & Maternal height $>90$ th percentile $(n=642)^{a}$ & High maternal education $(\mathrm{n}=3214)^{\mathrm{b}}$ & Single women $(\mathrm{n}=279)^{\mathrm{a}}$ \\
\hline \multicolumn{5}{|c|}{ Grandparents' level of education $^{c}$} \\
\hline Low $(\leq$ primary $)$ & 4443 & Reference & Reference & Reference \\
\hline Intermediate (secondary) & 1146 & $1.31[1.05,1.62]$ & $1.99[1.52,2.60]$ & $1.31[0.96,1.78]$ \\
\hline High (>secondary) & 912 & $1.75[1.41,2.18]$ & $4.24[2.63,6.86]$ & $1.12[0.76,1.64]$ \\
\hline \multicolumn{5}{|c|}{ Childhood social class (12 years) } \\
\hline Low & 1765 & Reference & Reference & Reference \\
\hline Intermediate & 3415 & $1.64[1.30,2.06]$ & $2.32[1.71,3.14]$ & $0.81[0.61,1.10]$ \\
\hline High & 1683 & $2.02[1.58,2.58]$ & $8.04[4.79,13.49]$ & $0.75[0.53,1.08]$ \\
\hline \multicolumn{5}{|c|}{ Childhood family structure (12 years) } \\
\hline No parents & 292 & Reference & Reference & Reference \\
\hline One parent & 733 & $0.99[0.66,1.48]$ & $1.35[0.74,2.46]$ & $0.76[0.45,1.30]$ \\
\hline Both parents & 5838 & $0.95[0.60,1.51]$ & $1.14[0.76,1.69]$ & $1.01[0.56,1.85]$ \\
\hline
\end{tabular}

a Models adjusted for maternal age.

b Models adjusted for the interaction with maternal age.

c Excluding 362 mothers with unknown grandparents education.

be similarly distributed in time. Still, an effect modification by age was not observed (data not shown).

Data on gestational age and birthweight was retrieved from medical files, not influenced by maternal recall. We used the SGA cut-offs provided by Kramer et al. (2001) because no national reference curves exist. Using a Canadian reference population may explain the high prevalence of SGA (14\%), since Portuguese babies are smaller (National Institute os Statistics (INE), 2005; Statistics Canada, 2005). Thus, part of the SGA babies may be healthy babies, the result of different exposures (Ananth and Vintzileos, 2009).

Table 3

Small-for-gestational-age babies (SGA) according to adult and childhood socioeconomic indicators from the 2005/2006 Portuguese birth cohort.

\begin{tabular}{|c|c|c|c|c|}
\hline & \multirow[t]{2}{*}{$\mathrm{n}$} & \multicolumn{3}{|c|}{ SGA $(n=997)$} \\
\hline & & $\mathrm{n}(\%)$ & p-Value ${ }^{*}$ & $\begin{array}{l}\text { OR [95\% CI] } \\
\text { (adjusted for } \\
\text { age and } \\
\text { gravidity) }\end{array}$ \\
\hline Maternal level of education & & & 0.003 & \\
\hline Low $(\leq$ primary $)$ & 2124 & $324(15.2)$ & & Reference \\
\hline $\begin{array}{l}\text { Intermediate (lower } \\
\text { secondary) }\end{array}$ & 1525 & $253(16.6)$ & & $1.01[0.84,1.21]$ \\
\hline High ( $\geq$ upper secondary) & 3214 & $420(13.1)$ & & $0.77[0.65,0.90]$ \\
\hline Marital status & & & $<0.001$ & \\
\hline Single & 279 & $60(21.5)$ & & Reference \\
\hline Cohabiting & 1481 & $246(16.6)$ & & $0.77[0.56,1.06]$ \\
\hline Married & 5103 & $691(13.5)$ & & $0.64[0.47,0.86]$ \\
\hline Maternal height & & & $<0.001$ & \\
\hline$<$ 10th percentile $(<153.0 \mathrm{~cm})$ & 674 & $151(22.4)$ & & $1.56[1.27,1.91]$ \\
\hline $\begin{array}{l}\text { 10-90th percentiles } \\
(153.0-169.0 \mathrm{~cm})\end{array}$ & 5547 & $794(14.3)$ & & Reference $^{\mathrm{b}}$ \\
\hline$>90$ th percentile $(>169.0 \mathrm{~cm})$ & 642 & $52(8.1)$ & & $0.62[0.46,0.83]$ \\
\hline Grandparents' level of education ${ }^{\mathrm{a}}$ & & & 0.972 & \\
\hline Low $(\leq$ primary $)$ & 4443 & $648(14.6)$ & & Reference \\
\hline Intermediate (secondary) & 1146 & $164(14.3)$ & & $0.93[0.78,1.12]$ \\
\hline High (>secondary) & 132 & $132(14.5)$ & & $0.98[0.80,1.20]$ \\
\hline Childhood social class ( 12 years) & & & 0.848 & \\
\hline Low & 1765 & $259(14.7)$ & & Reference \\
\hline Intermediate & 3415 & $488(14.3)$ & & $0.90[0.76,1.06]$ \\
\hline High & 1683 & $250(14.8)$ & & $0.95[0.78,1.15]$ \\
\hline $\begin{array}{l}\text { Childhood family structure } \\
\text { (12 years) }\end{array}$ & & & 0.506 & \\
\hline No parents & 292 & $42(14.4)$ & & Reference \\
\hline One parent & 733 & $117(16.0)$ & & $1.10[0.75,1.62]$ \\
\hline Both parents & 5838 & $838(14.4)$ & & $0.98[0.70,1.37]$ \\
\hline
\end{tabular}

* From chi-squared test.

a Excluding 362 mothers with unknown grandparents education.

b Also adjusted for maternal pre-pregnancy weight.

\section{Interpretation}

Adult socioeconomic conditions seem to be more important than previous childhood environment, at least among women that grew in more disadvantaged contexts. These results are not totally in accordance with the acknowledged independent effect of childhood background (Astone et al., 2007; Emanuel et al., 1992) and upward mobility (Colen et al., 2006). This might be explained by the fact that women grew up in periods of great economic and educational improvements, very different from the settings evaluated in the published literature. Women showed a marked increase in education in relation to their parents (while almost $70 \%$ of grandparents only achieved primary education corresponding to 4 schooling years, the proportion was 30\% in the mothers ( 6 schooling years)). Women seem to benefit from an increase in education and part of the benefit appears to be related with the achieved level and part with the upward process: when compared to women with low adult education, an increase from low childhood class to the intermediate level did not reduce the risk of SGA. Small increases in socioeconomic position have not been reflected in better pregnancy outcomes, probably because the point of origin was particularly low. Together with an upward mobility protection, long-lasting effects of advantaged social environment were also found: in women from more affluent childhood backgrounds (highly educated grandparents or from high social class) - that were, a priori, at lower risk - SGA did not differ according to the achieved level. Those who fell in the social hierarchy did not present an increased risk of SGA. However, downgrading was a particularly rare phenomenon. Thus, wealthy childhood environment may, at least, shape adult social destinations, decreasing the probability of downgrading social conditions. The magnitude of the association between height and offspring growth restriction differed by childhood social strata. It is known that growth is influenced by nutritional and psychosocial factors acting during childhood and adolescence (Wadsworth et al., 2002). So, height may be a proxy of childhood social conditions. This relation has been extensively described (Hypponen et al., 2004; Lawlor et al., 2003; Kramer, 1987) but, to the best of our knowledge, this is the first study reporting that being shorter is more strongly associated with SGA in women with a least deprived childhood than in poorer ones. In average, those with a more deprived background were shorter than those from intermediate/high classes. Although we cannot control for grandparents' stature, it is plausible that they had shorter parents. Thus, low height distribution may somehow reflect familial short stature (although possibly resulting from long-lasting exposure to adversity). In more advantaged childhood backgrounds, being of short stature might represent exposure to pathological processes that resulted in an increased risk of SGA but were not related with the social background (Lawlor et al., 2003; Addo et al., 2013). 
Table 4

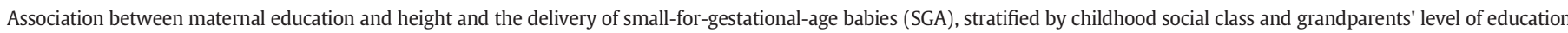
from the 2005/2006 Portuguese birth cohort.

\begin{tabular}{|c|c|c|c|c|c|c|c|}
\hline & & \multicolumn{6}{|l|}{ SGA (OR [95\% CI]) } \\
\hline & & \multicolumn{3}{|c|}{ Childhood social class } & \multicolumn{3}{|c|}{ Grandparents' level of education ${ }^{a}$} \\
\hline & & $\begin{array}{l}\text { Low } \\
(\mathrm{n}=1765)\end{array}$ & $\begin{array}{l}\text { Intermediate } \\
(\mathrm{n}=3415)\end{array}$ & $\begin{array}{l}\text { High } \\
(\mathrm{n}=1683)\end{array}$ & $\begin{array}{l}\text { Low } \\
(\mathrm{n}=4443)\end{array}$ & $\begin{array}{l}\text { Intermediate } \\
(\mathrm{n}=1146)\end{array}$ & $\begin{array}{l}\text { High } \\
(\mathrm{n}=912)\end{array}$ \\
\hline \multirow[t]{7}{*}{$\begin{array}{l}\text { Adjusted for maternal } \\
\text { age and gravidity }\end{array}$} & $\begin{array}{l}\text { Maternal level of education } \\
\text { Low }\end{array}$ & Reference & Reference & Reference & Reference & Reference & Reference \\
\hline & Intermediate & $0.95[0.66,1.36]$ & $1.02[0.80,1.31]$ & $1.20[0.60,2.41]$ & $1.00[0.81,1.24]$ & $1.19[0.69,2.07]$ & $0.34[0.11,1.06]$ \\
\hline & High & $0.66[0.46,0.97]$ & $0.75[0.59,0.96]$ & $0.86[0.45,1.64]$ & $0.74[0.61,0.92]$ & $0.75[0.45,1.26]$ & $0.41[0.15,1.12]$ \\
\hline & Maternal height ${ }^{\mathrm{b}}$ & & & & & & \\
\hline & $<10$ th percentile & $1.30[0.91,1.85]$ & $1.59[1.18,2.15]$ & $1.94[1.21,3.12]$ & $1.51[1.18,1.92]$ & $1.73[1.00,2.98]$ & $1.38[0.69,2.75]$ \\
\hline & 10-90th percentiles & Reference & Reference & Reference & Reference & Reference & Reference \\
\hline & $>90$ th percentile & $1.10[0.60,2.04]$ & $0.46[0.29,0.74]$ & $0.66[0.40,1.12]$ & $0.61[0.41,0.92]$ & $0.55[0.27,1.12]$ & $0.66[0.34,1.28]$ \\
\hline \multirow[t]{8}{*}{ Mutually adjusted } & Maternal level of education ${ }^{c}$ & & & & & & \\
\hline & Low & Reference & Reference & Reference & Reference & Reference & Reference \\
\hline & Intermediate & $0.97[0.68,1.40]$ & $1.06[0.82,1.36]$ & $1.22[0.60,2.46]$ & $1.03[0.83,1.28]$ & $1.24[0.71,2.16]$ & $0.33[0.10,1.02]$ \\
\hline & High & $0.68[0.46,0.99]$ & $0.80[0.63,1.03]$ & $0.90[0.47,1.73]$ & $0.79[0.64,0.97]$ & $0.80[0.47,1.35]$ & $0.41[0.15,1.12]$ \\
\hline & Maternal height $^{\mathrm{d}}$ & & & & & & \\
\hline & $<10$ th percentile & $1.26[0.89,1.80]$ & $1.55[1.15,2.10]$ & $1.88[1.17,3.03]$ & $1.46[1.14,1.87]$ & $1.67[0.96,2.88]$ & $1.37[0.68,2.76]$ \\
\hline & 10-90th percentiles & Reference & Reference & Reference & Reference & Reference & Reference \\
\hline & $>90$ th percentile & $1.15[0.62,2.13]$ & $0.48[0.30,0.76]$ & $0.68[0.40,1.14]$ & $0.64[0.35,0.96]$ & $0.56[0.28,1.16]$ & $0.66[0.29,1.29]$ \\
\hline
\end{tabular}

${ }^{a}$ Excluding 362 mothers with unknown grandparents education.

b Models are also adjusted for maternal pre-pregnancy weight.

c Models adjusted for maternal age, gravidity and height.

d Models adjusted for maternal age, gravidity, pre-pregnancy weight and maternal education.

Part of the association between height and SGA could be related with maternal weight. Taller women are more likely to be heavier, decreasing the risk of growth restriction (Kramer, 1987). However, estimates remained statistically significant after adjustment for maternal weight.

Marital status was associated with SGA independently of childhood social conditions: single and cohabiting mothers showed, respectively, $57 \%$ and $22 \%$ higher odds of SGA than married ones. Although cohabitation has become frequent and well accepted by the society, unmarried women remain more likely to be exposed to adverse health behaviours and to the lack of pregnancy planning and of social support (Shah et al., 2011; Raatikainen et al., 2005).

\section{Conclusion}

In a country that faced major social changes, childhood background still influenced educational achievement. However, a sufficient increase in education seems to overcome disadvantage earlier in life. Maternal growth was related with SGA not only reflecting social background but also by other mechanisms beyond economic conditions. Future research is needed to estimate other early exposures and to evaluate how social transmission changes in time and in countries with different cultural and economic characteristics.

Supplementary data to this article can be found online at http://dx. doi.org/10.1016/j.ypmed.2014.11.027.

\section{Funding}

This project was funded by Programa Operacional de Saúde - Saúde XXI, Quadro Comunitário de Apoio III (75\% from FEDER and 25\% from the Regional Department of Ministry of Health (ARS-Norte) - approved 28/12/2004 Ref: 15-01-01-FDR-00197. This work was supported by the Portuguese Foundation for Science and Technology (grant SFRH/BD/ $66159 / 2009$ to Correia S.).

Sponsors were not involved in the study design; in the collection, analysis and interpretation data; in the writing of the report; and in the decision to submit the paper for publication.

\section{Authors' contribution}

Sofia Correia was responsible for the study concept, collection, analysis and interpretation of data and first draft of the manuscript; and Henrique Barros was responsible for the cohort study design, study concept and interpretation of data and revised the manuscript critically for important intellectual content. Both authors approved the final version of the manuscript.

\section{Conflict of interest statement}

The authors report no conflict of interest.

\section{Acknowledgments}

The authors gratefully acknowledge Raquel Lucas for her contribution. The authors acknowledge the families enrolled in Generation XXI for their generosity, all members of the research team for their enthusiasm and perseverance and the participating hospitals and their staff for their help and support.

\section{References}

Addo, O.Y., Stein, A.D., Fall, C.H., et al., 2013. Maternal height and child growth patterns. J. Pediatr. 163 (2), 549-554. http://dx.doi.org/10.1016/j.jpeds.2013.02.002 (Aug).

Albert, C., Davia, M.A., 2011. Education is a key determinant of health in Europe: a comparative analysis of 11 countries. Health Promot. Int. 26 (2), 163-170. http://dx.doi. org/10.1093/heapro/daq059 (Jun).

Alves, E., Correia, S., Barros, H., et al., 2012. Prevalence of self-reported cardiovascular risk factors in Portuguese women: a survey after delivery. Int. J. Public Health 57 (5), 837-847. http://dx.doi.org/10.1007/s00038-012-0340-6 (Oct).

Ananth, C.V., Vintzileos, A.M., 2009. Distinguishing pathological from constitutional small for gestational age births in population-based studies. Early Hum. Dev. 85 (10), 653-658. http://dx.doi.org/10.1016/j.earlhumdev.2009.09.004 (Oct).

Astone, N.M., Misra, D., Lynch, C., 2007. The effect of maternal socio-economic status throughout the lifespan on infant birthweight. Paediatr. Perinat. Epidemiol. 21 (4) 310-318. http://dx.doi.org/10.1111/j.1365-3016.2007.00821.x (Jul).

Barreto, A., 2011. Social change in Portugal. In: Pinto, A.C. (Ed.), Contemporary Portugal: Politics, Society and Culture, 2nd ed. New York SSM-Columbia University Press, pp. 193-224.

Blumenshine, P., Egerter, S., Barclay, C.J., et al., 2010. Socioeconomic disparities in adverse birth outcomes: a systematic review. Am. J. Prev. Med. 39 (3), 263-272. http://dx.doi. org/10.1016/j.amepre.2010.05.012 (Sep).

Colen, C.G., Geronimus, A.T., Bound, J., et al., 2006. Maternal upward socioeconomic mobility and black-white disparities in infant birthweight. Am. J. Public Health 96 (11), 2032-2039. http://dx.doi.org/10.2105/ajph.2005.076547 (Nov). 
Collins Jr., J.W., David, R.J., Prachand, N.G., et al., 2003. Low birth weight across generations. Matern. Child Health J. 7 (4), 229-237 (Dec).

Collins Jr., J.W., David, R.J., Rankin, K.M., et al., 2009. Transgenerational effect of neighborhood poverty on low birth weight among African Americans in Cook County, Illinois. Am. J. Epidemiol. 169 (6), 712-717. http://dx.doi.org/10.1093/aje/kwn402 (Mar 15).

Collins, J.W., Rankin, K.M., David, R.J., 2011. Low birth weight across generations: the effect of economic environment. Matern. Child Health J. 15 (4), 438-445. http://dx. doi.org/10.1007/s10995-010-0603-x (May).

Emanuel, I., Filakti, H., Alberman, E., et al., 1992. Intergenerational studies of human birthweight from the 1958 birth cohort. 1. Evidence for a multigenerational effect. Br. J. Obstet. Gynaecol. 99 (1), 67-74 (Jan).

Graham, H., Power, C., 2004. Childhood disadvantage and health inequalities: a framework for policy based on lifecourse research. Child Care Health Dev. 30 (6), 671-678 (Nov)

Hypponen, E., Power, C., Smith, G.D., 2004. Parental growth at different life stages and offspring birthweight: an intergenerational cohort study. Paediatr. Perinat. Epidemiol. 18 (3), 168-177 (May).

Kramer, M.S., 1987. Determinants of low birth weight: methodological assessment and meta-analysis. Bull. World Health Organ. 65 (5), 663-737.

Kramer, M.S., Seguin, L., Lydon, J., et al., 2000. Socio-economic disparities in pregnancy outcome: why do the poor fare so poorly? Paediatr. Perinat. Epidemiol. 14 (3) 194-210 (Jul).

Kramer, M.S., Platt, R.W., Wen, S.W., et al., 2001. A new and improved population-based Canadian reference for birth weight for gestational age. Pediatrics 108 (2), E35 (Aug).

Larsen, P.S., Kamper-Jorgensen, M., Adamson, A., et al., 2013. Pregnancy and birth cohort resources in Europe: a large opportunity for aetiological child health research. Paediatr. Perinat. Epidemiol. 27 (4), 393-414. http://dx.doi.org/10.1111/ppe.12060 (Jul).

Lawlor, D.A., Davey Smith, G., Ebrahim, S., 2003. Association between leg length and offspring birthweight: partial explanation for the trans-generational association between birthweight and cardiovascular disease: findings from the British Women's Heart and Health Study. Paediatr. Perinat. Epidemiol. 17 (2), 148-155 (Apr).

Lu, M.C., Halfon, N., 2003. Racial and ethnic disparities in birth outcomes: a life-course perspective. Matern. Child Health J. 7 (1), 13-30 (Mar).

Lumey, L.H., Stein, A.D., 1997. Offspring birth weights after maternal intrauterine undernutrition: a comparison within sibships. Am. J. Epidemiol. 146 (10), 810-819 (Nov 15).
Marmot, M., Allen, J., Bell, R., et al., 2012. WHO European review of social determinants of health and the health divide. Lancet 380 (9846), 1011-1029. http://dx.doi.org/10. 1016/S0140-6736(12)61228-8 (Sep 15).

Mortensen, L.H., Diderichsen, F., Arntzen, A., et al., 2008. Social inequality in fetal growth: a comparative study of Denmark, Finland, Norway and Sweden in the period 19812000. J. Epidemiol. Community Health 62 (4), 325-331 (Apr).

National Institute os Statistics (INE), 2005. Live births in Portugal (2005) [database on the Internet]. www.ine.pt ([accessed on December 2013]. Available from:).

Poulton, R., Caspi, A., Milne, B.J., et al., 2002. Association between children's experience of socioeconomic disadvantage and adult health: a life-course study. Lancet 360 (9346), 1640-1645 (Nov 23)

Raatikainen, K., Heiskanen, N., Heinonen, S., 2005. Marriage still protects pregnancy. BJOG 112 (10), 1411-1416. http://dx.doi.org/10.1111/j.1471-0528.2005.00667.x (Oct).

Raisanen, S., Gissler, M., Sankilampi, U., et al., 2013. Contribution of socioeconomic status to the risk of small for gestational age infants - a population-based study of 1,390,165 singleton live births in Finland. Int. J. Equity Health 12, 28. http://dx.doi. org/10.1186/1475-9276-12-28.

Robins, J.M., Greenland, S., 1992. Identifiability and exchangeability for direct and indirect effects. Epidemiology 3 (2), 143-155 (Mar)

Shah, P.S., Zao, J., Ali, S., 2011. Maternal marital status and birth outcomes: a systematic review and meta-analyses. Matern. Child Health J. 15 (7), 1097-1109. http://dx.doi. org/10.1007/s10995-010-0654-z (Oct).

Sigle-Rushton, W., Hobcraft, J., Kiernan, K., 2005. Parental divorce and subsequent disadvantage: a cross-cohort comparison. Demography 42 (3), 427-446 (Aug).

Statistics Canada, 2005. Mean and Median Birth Weight (Live Births), by Sex, Canada, Provinces and Territories (2005). Statistics Canada ([15 December 2013]; Available from: http://www.statcan.gc.ca/)

Teixeira, C., 2013. Caesarean - A Role For Culture, Society and Health Care. University of Porto Medical School, Porto (Available from: http://repositorio-aberto.up.pt/handle/ 10216/70825).

Wadsworth, M.E., Hardy, R.J., Paul, A.A., et al., 2002. Leg and trunk length at 43 years in relation to childhood health, diet and family circumstances; evidence from the 1946 national birth cohort. Int. J. Epidemiol. 31 (2), 383-390 (Apr).

Ward, M.M., 2011. Concordance of sibling's recall of measures of childhood socioeconomic position. BMC Med. Res. Methodol. 11, 147. http://dx.doi.org/10.1186/1471-228811-147. 